\title{
Risk factores of delayed diaphragmatic ruptures
}

\begin{abstract}
In contrast to the world thoracic literature, less attention has been payed to blunt diaphragmatic ruptures in hungarian surgical literature.Based on 12 cases of blunt traumatic diaphragmatic rupture at Thoracic Surgical Clinic (1981-2001), circumstances of late recognition is evaluated. In majority of patients history of thoracic and/or abdominal truma has been totaly forgotten, resulting fals diagnosis of tension pneumothorax in one. In 3 others the diaphragmatic tear was missed during the previous laparotomy in one or considered as a hiatal hernia in the second and a really recurrent hernia was confused with a posttraumatic diaphragmatic palsy in the third. A subgroup of this entity, the two-steps ruture of one patient, may considered as a life-threatening urgency, when early approach is mandatory. In this series for diaphragmatic reconstruction in dominantly left-sided rutures (10) a similar sided postreolateral thoracotomy were used, and right-sided in the remaing 2 , buttressed in only one, without mortality and recurrence. The delay of diagnosis may considered as the primordial factor of mortality. Even in long-lasting occult cases all efforts are necessary to solve the diagnostic dilemma, befor fatal visceral strangulation, befor development of feco-pneumothorax, gastric necrosis or tension pneumothorax. Suspition of the thoracoabdominal trauma may consisered as an important factor of true diagnosis and for pervention of iatrogenic surgical events.
\end{abstract}

Keywords: Diaphragmatic rupture; Missed thoracic and/or abdominal trauma; Delayed recognition; Risk factors
Volume 4 Issue 5 - 2017

\section{Kotsis L, Kostic SZ,Vadász P}

Department of Thoracic Surgical, Korányi National Institute for Pulmonology, Hungary

Correspondence: Kotsis L, Department of Thoracic Surgical,
Korányi National Institute for Pulmonology, Budapest, Hungary, Email lkotsisdr@gmail.com

Received: July 17, 2017 | Published: November 17, 2017

\section{Introduction}

In close connection with increasing trafic and car accidents phenomenon of modern life- large series of diaphragmatic ruptures, ${ }^{1-4}$ including even right sided one $\mathrm{e}^{5-8}$ were published in world literature.

The aim of this retospective analysis is to evaluate the difficulties of accurate diagnosis of blunt traumatic ruptures of diaphragm and to call attention on serious complications of delayed recognition.

\section{Material and methods}

From 1981 to 200112 patients with chronic occult diaphragmatic disruption have been managed at our Clinic. All but two were lefsided hernias with delayed presentation, at least 6month after injury. In the majority of the cases the fact of blunt thoracic and/or abdominal trauma have been forgotten and the injurys to the diaphragm were not suspected befor admission, resulting fals diagnosis of tension pneumothorax in one. In 3 other cases rupture of the left-seded diaphragm was missed at prior laparotomy, a recurrent left-sided hernia was interpreted at the previous Institute as posttraumatic phrenicus nerv paly and erroneous diagnosis of massive hiatal hernia was done in the thired patient. In case of a young patient the leftsided rupture with gastric stangulation developed 7 days after trauma, representing a veritable two-steps rupture.

The correct diagnosis of occult diaphragmatic hernia was established preoperativelly in all instances. The left posterolateral thoracotomy was the preferred approach, except 3 cases when a left thoracolaparotomy or right thoracotomy were require for hernia repair. We used interrupted suture, buttressed with vicryl mesh at only one patient. In almost all cases a visceral herniation (stomach, intestine, spleen, liver and omentum) into the chest cavity was present, most commonly through the paracardiac area in left and central tendon on right side.

\section{Results}

None of the patints was lost and no recurrence occured in the 1 to 10years follow-up period.

\section{Discussion}

The delay of diagnosis in latent blunt diaphragmatic ruptures may be attributed to several factores such as superfitial history, fals or erroneous diagnosis of some thoracic x-ray findings. On contrary suspition of a thoracoabdominal trauma may be considered as an important factor toward to a true diagnosis of occult diaphragmatic ruptures. Majority of the authors stress the importance of the delayed diagnosis in the developement of the life threatening complications, including fatal visceral strangulation with stomac necrosis, ${ }^{9}$ colopleural fistula with pneumothorax, ${ }^{10,11}$ tension fecopneumothorax. ${ }^{12-15}$ Also this is an important factor for prevention of iatrogenic surgical events. Even in long- lasting occult cases, careful history, abnormalities of plain chest roentgenogram, CT scan and barium meal studies of digestive tract may solve the diagnostic dilemma.

However spontaneous or postoperative phrenicus nerv palsy or a strangulated Bochdalek type diaphragmatic hernia may represent a veritable differential diagnostic problem. Extensive adhesions between the herniated viscerea and the lung or pericardium are difficult to be taken down through laparotomy so transthoracic approach for diaphragmatic repair seems to be the best approach. ${ }^{16}$ This series like other lage series reflects that delayed recognition of diaphragmatic rupture ${ }^{17,18}$ may be considered as primordial factor of mortality.

\section{Acknowledgements}

None.

\section{Conflict of interest}

Author declares that there is no conflict of interest. 


\section{References}

1. Dirican A, Jimaz M, Unal B, et al. Acute traumatic diaphragmatic ruptures: a retrospective study of 48 cases. Surg Today. 2011;41(10):1352-1356.

2. Gwely NN. Outcome of blunt diaphragmatic rupture. Analysis of $44 \mathrm{ca}-$ ses. Asian Cardiovascular and Thoracic Annals. 2010;18(3):240-243.

3. Turhan K, Makay O. Traumatic diaphragmatic rupure: look to see. Eur J Cardiothorac Surg. 2008;33(6):1082-1085.

4. Al-Refaie RE, Awad E, Mokbel EM. Blunt traumatic rupture of diaphragm: a retrospective observational study of 48 patients. Interact Cardiovasc Thorac Surg. 2009;9:45-49.

5. Hromadka P Cemohorsky S, Bader M, Skach J, et al. Right-sided posttraumatic rupture of the diaphragm. Rozhl Chir. 2010;89(10):638-641.

6. Vilallonga R, Pastor V, Alvares L. Right-sided diaphragmatic rupture after blunt trauma. An unusual entity. Wold J Emerg Surg. 2011;6:3.

7. Wiliam RR, Sankhala D, Al-Qassabi. Traumatic rupture of right hemidiaphragm: diagnosis aided by computerized tomography and imagine reformation: a case report. Sultan Qaboos Univ Med J. 2008;8(2):219-222.

8. Kozak O, Mentes O, Harlak A, et al. Late presentation of blunt right diaphragmatic rupture (hepatic hernia). Am $J$ Emerg Med. 2008;26(5):638-641.

9. Onakpoya U, Ogunromby A, Adenekan A, et al. Strangulated tension viscerothorax with gangrene of the stomach in missed traumatic diaphragmatic rupture. ISRN Surg. 2011;2011:458390.
10. Pierce BA, Elliot MJ. Perforation of intrathoracic colon causing pneumothorax. Thorax. 1983;38(12):959-960.

11. Radin DR, Ray MJ. Strangulated diaphragmatic hernia with pneumothorax due to colopleural fistula. Am J Roengenol. 1986;146:321-322.

12. Brun RC, Curt JRN. A case of traumatic diaphragmatic hernia presenting as acute tension pneumothorax. Injury. 1987;18(5):355-356.

13. Matei P, Wiebke E, Lipsett P. Tension pneumothorax as a presentation of traumatic diaphragmatic hernia. South Med J. 1992;85(8):847-850.

14. Seeling MH, Klinger PJ, Schönleben K. Tension fecopneumothorax due to colonic perforation in a diaphragmatic hernia. Chest. 1999;115(1):288-191.

15. Montesor E, Bortolasi L, Modena S, et al. Delayed traumatic hernia of the diaphragm presenting with hypertensive pneumothorax: case report and review of the literature. Giornale Chir. 1997;18(5):295-296.

16. Kotsis L, Csekeő A, Karoly O. Latent diaphragmatic hernia: a surgical challenge. Chest. 2002;121(3):1006.

17. Kaths M, Ebert M, Galle PR, et al. Late consequences of traumatic rupture of the diaphragm. Thorac Cardiovasc Surg. 2013;61(3):267-269.

18. Rashid F, Chakrabarty MM, Singh R, et al. A review on delayed presentation of diaphragmatic rupture. Wold J Emerg Surg. 2009;4:32. 